Conclusion: In the 16-week EQUATOR trial, the effects of filgotinib on key efficacy endpoints were generally consistent across a range of subgroups based on patient, disease, and treatment characteristics.

References:

[1] Mease P, et al. Lancet 2018;392:2367-77.

Acknowledgments: The EQUATOR trial was sponsored by Galapagos NV and co-funded by Galapagos NV and Gilead Sciences. Medical writing support was provided by Hannah Mace MPharmacol, CMPP (Aspire Scientific Ltd, Bollington, UK) and funded by Galapagos NV (Mechelen, Belgium).

Disclosure of Interests: Philip Helliwell: None declared, Filip van den Bosch Consultant of: AbbVie, Celgene Corporation, Eli Lilly, Galapagos, Janssen, Novartis, Pfizer, and UCB, Speakers bureau: AbbVie, Celgene Corporation, Eli Lilly, Galapagos, Janssen, Novartis, Pfizer, and UCB, Laura C Coates: None declared, Dafna D Gladman Grant/research support from: AbbVie, Amgen Inc., BMS, Celgene Corporation, Janssen, Novartis, Pfizer, UCB - grant/research support, Consultant of: AbbVie, Amgen Inc., BMS, Celgene Corporation, Janssen, Novartis, Pfizer, UCB - consultant, Chantal Tasset Shareholder of: Galapagos (share/warrant holder), Employee of: Galapagos, Luc Meuleners Employee of: Galapagos, Leen Gilles Consultant of: Galapagos, Lien Gheyle Employee of: Galapagos, Mona Trivedi Shareholder of: Amgen and Gilead Sciences, Employee of: Gilead Sciences, Muhsen Alani Employee of: Gilead Sciences, Robin Besuyen Shareholder of: Galapagos, Employee of: Galapagos, Philip J Mease Grant/research support from: Abbott, Amgen, Biogen Idec, BMS, Celgene Corporation, Eli Lilly, Novartis, Pfizer, Sun Pharmaceutical, UCB - grant/ research support, Consultant of: Abbott, Amgen, Biogen Idec, BMS, Celgene Corporation, Eli Lilly, Novartis, Pfizer, Sun Pharmaceutical, UCB - consultant, Speakers bureau: Abbott, Amgen, Biogen Idec, BMS, Eli Lilly, Genentech, Janssen, Pfizer, UCB - speakers bureau

DOI: 10.1136/annrheumdis-2020-eular.2495

\section{FRI0344 \\ THE LONG-TERM EFFECT OF TREATING PSORIATIC ARTHRITIS WITH THE JANUS KINASE 1-SELECTIVE INHIBITOR FILGOTINIB ON LIPID PROFILES: AN ANALYSIS OF THE EQUATOR AND EQUATOR2 TRIALS}

M. E. Husni ${ }^{1}$, D. D. Gladman ${ }^{2}$, P. Helliwell ${ }^{3}$, F. Van den Bosch ${ }^{4}$, C. Tasset $^{5}$, L. Meuleners ${ }^{5}$, L. Gilles ${ }^{6}$, L. Gheyle ${ }^{5}$, M. Trivedi ${ }^{7}$, M. Alani ${ }^{7,8}$, R. Besuyen ${ }^{9}$, P. J. Mease ${ }^{8,10} .{ }^{1}$ Cleveland Clinic: Orthopedic and Rheumatologic Institute, Cleveland, $\mathrm{OH}$, United States of America; ${ }^{2}$ University of Toronto, Toronto, Canada; ${ }^{3}$ University of Leeds, Leeds, United Kingdom; ${ }^{4}$ Ghent University Hospital, Ghent, Belgium; ${ }^{5}$ Galapagos NV, Mechelen, Belgium; ${ }^{6}$ LACO, contracted by Galapagos NV, Mechelen, Belgium; ${ }^{7}$ Gilead Sciences, Inc, Foster City, CA, United States of America; ${ }^{8}$ University of Washington, Seattle, United States of America; ${ }^{9}$ Galapagos BV, Leiden, Netherlands; ${ }^{10}$ Swedish Medical Centre, Seattle, United States of America

Background: Cardiovascular (CV) comorbidities are common in psoriatic arthritis (PsA); patients are at high risk for major adverse cardiovascular events (MACE). ${ }^{1}$ In the Phase 2, double-blind, randomized EQUATOR trial, significant improvements across multiple PsA domains were observed with the oral selective Janus kinase (JAK) 1 inhibitor filgotinib compared with placebo. ${ }^{2}$ Inhibition of JAK signal transducer and activator of transcription signaling is associated with raised serum lipids. ${ }^{3}$

Objectives: To evaluate the effects of filgotinib on the lipid profile of PsA patients and determine if those with higher MACE risk show similar changes in lipid profile compared with the overall population.

Methods: In EQUATOR, 131 patients with active PsA received filgotinib $200 \mathrm{mg}$ $(n=65)$ or placebo $(n=66)$ once daily for 16 weeks. Patients completing EQUATOR could enter the ongoing EQUATOR2 open-label extension (OLE; NCT03320876), in which patients receive filgotinib $200 \mathrm{mg}$ for up to 148 weeks. Effects of filgotinib on total cholesterol (TC), high-density lipoprotein cholesterol (HDL-C), low-density lipoprotein cholesterol (LDL-C), and TC/HDL-C ratio at OLE Week 52 (68 weeks after EQUATOR initiation) were analyzed. In a post hoc analysis, patients were classified into subgroups according to presence/absence of obesity (baseline body mass index [BMI]; $\geq 30 \mathrm{vs}<30 \mathrm{~kg} / \mathrm{m}^{2}$, respectively), diabetes mellitus, arterial hypertension $(\geq 130 / 80 \mathrm{mmHg})$, hyperlipidemia, and metabolic syndrome. Changes in lipid levels were explored graphically.

Results: 124 patients (95\%) completed EQUATOR; 122 (93\%) enrolled in the OLE. Of these, 11 patients (9\%) discontinued treatment by OLE Week 52. Median (range) exposure to filgotinib was 66.0 (0.4-104.1) weeks. In the OLE, TC, LDL-C, and HDL-C levels increased versus baseline with filgotinib, resulting in a decreased TC/HDL-C ratio. Changes in lipid levels were consistent irrespective of presence of obesity $(n=56$; Fig), diabetes $(n=53)$, arterial hypertension $(n=80)$, hyperlipidemia $(n=108)$, or metabolic syndrome $(n=36)$; baseline lipid values were greater in the higher risk groups. In patients who were assigned placebo in the randomized controlled trial (RCT), HDL-C increased on switching to filgotinib in the OLE (in a manner similar to that seen in filgotinib-treated patients during the RCT), and remained elevated compared with baseline (Fig). Triglyceride levels remained stable throughout, across all subgroups. Seventeen patients (13\%) were taking lipid-lowering drugs (LLDs) prior to the start of the trial (and continued to do so); the effect of filgotinib on the lipid profile in these patients was similar to that in the overall population. During the RCT phase, another six patients in the filgotinib group and one in the placebo group began taking LLDs. Conclusion: In patients exposed to filgotinib for $\geq 52$ weeks, the effects on lipid profile were consistent regardless of baseline $\mathrm{CV}$ risk. Lipid changes included an elevation in TC and HDL-C, with a decrease in TC/HDL-C ratio.

\section{References:}

[1] Haddad A \& Zisman D. Rambam Maimonides Med J 2017;8:e0004

[2] Mease P, et al. Lancet 2018;392:2367-77

[3] Sands B, et al. Clin Gastroenterol Hepatol 2020;18:123-32

Figure 1. Change from baseline in lipid profile in non-obese and obese patients

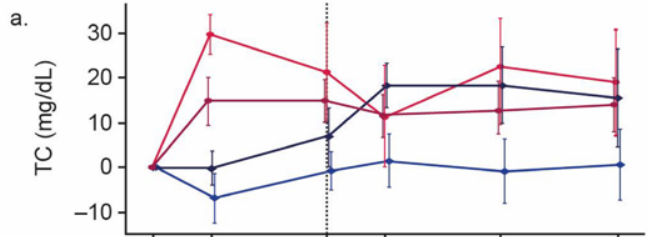

b.
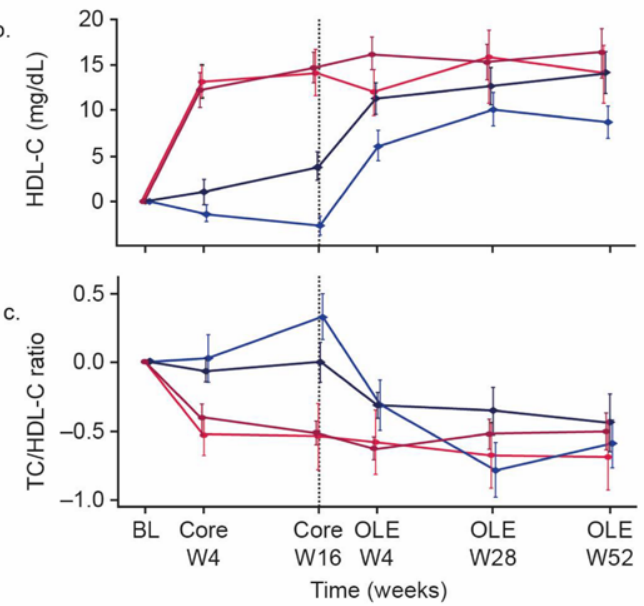

- FIL/FIL, non-obese $(B M I<30)(n=40) \quad$ FIL/FIL, obese $(B M I \geq 30)(n=25)$

$\rightarrow$ PBO/FIL, non-obese $(B M I<30)(n=35) \rightarrow P B O / F I L$, obese $(B M I \geq 30)(n=31)$

$\mathrm{BL}$, baseline; BMI, body mass index; FIL, filgotinib; HDL-C, high-density lipoprotein cholesterol; OLE, open-label extension; PBO, placebo; TC, total cholesterol; W, Week

Acknowledgments: Studies were sponsored by Galapagos NV; co-funded by Galapagos NV and Gilead Sciences. Writing support from Hannah Mace MPharmacol, CMPP (Aspire Scientific Ltd, Bollington, UK) was funded by Galapagos NV (Mechelen, Belgium).

Disclosure of Interests: M Elaine Husni Grant/research support from: Pfizer Consultant of: AbbVie, Bristol-Myers Squibb, Eli Lilly, Janssen, Novartis, Regeneron, and UCB, Dafna D Gladman Grant/research support from: AbbVie, Amgen Inc., BMS, Celgene Corporation, Janssen, Novartis, Pfizer, UCB - grant/research support, Consultant of: AbbVie, Amgen Inc., BMS, Celgene Corporation, Janssen, Novartis, Pfizer, UCB - consultant, Philip Helliwell: None declared, Filip van den Bosch Consultant of: AbbVie, Celgene Corporation, Eli Lilly, Galapagos, Janssen, Novartis, Pfizer, and UCB, Speakers bureau: AbbVie, Celgene Corporation, Eli Lilly, Galapagos, Janssen, Novartis, Pfizer, and UCB, Chantal Tasset Shareholder of: Galapagos (share/warrant holder), Employee of: Galapagos, Luc Meuleners Employee of: Galapagos, Leen Gilles Consultant of: Galapagos, Lien Gheyle Employee of: Galapagos, Mona Trivedi Shareholder of: Amgen and Gilead Sciences, Employee of: Gilead Sciences, Muhsen Alani Employee of: Gilead Sciences, Robin Besuyen Shareholder of: Galapagos, Employee of: Galapagos, Philip J Mease Grant/research support from: Abbott, Amgen, Biogen Idec, BMS, Celgene Corporation, Eli Lilly Novartis, Pfizer, Sun Pharmaceutical, UCB - grant/research support, Consultant of: Abbott, Amgen, Biogen Idec, BMS, Celgene Corporation, Eli Lilly Novartis, Pfizer, Sun Pharmaceutical, UCB - consultant, Speakers bureau: Abbott, Amgen, Biogen Idec, BMS, Eli Lilly, Genentech, Janssen, Pfizer, UCB - speakers bureau

DOI: 10.1136/annrheumdis-2020-eular.2494 